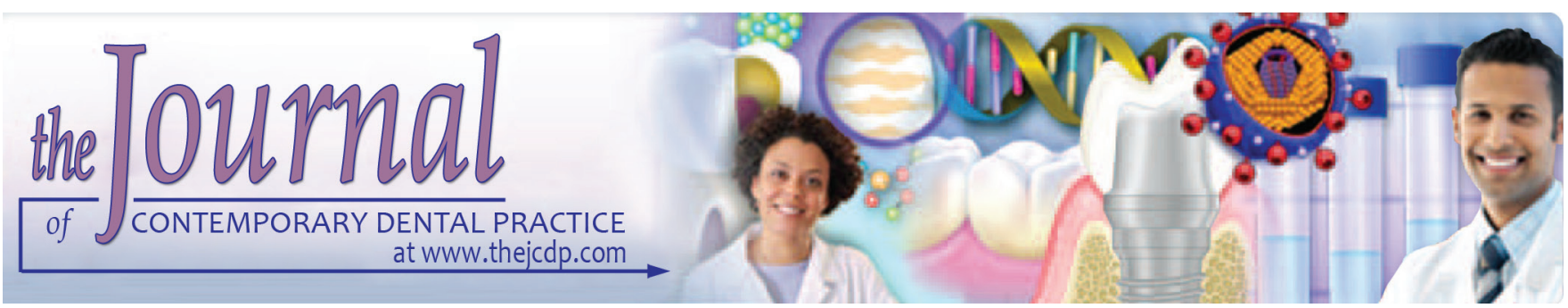

\title{
Effect of Periodontal Therapy on Crevicular Fluid Interleukin-18 Level in Periodontal Health and Disease in Central Maharashtra (India) Population
}

\author{
${ }^{1}$ Monica J Mahajani, ${ }^{2}$ Varsha A Jadhao, ${ }^{3}$ Pooja S Wankhade, ${ }^{4}$ Emmanuel Samson \\ ${ }^{5}$ Vishwas D Acharya, ${ }^{6}$ Pawankumar D Tekale
}

\begin{abstract}
Aim: The incidence and progression of the periodontal disease depend on periodontal microflora and the multifaceted response of the host, and these interactions are mediated by cytokines and chemokines. Interleukin-18 (IL-18) is a proinflammatory cytokine of the IL-1 superfamily. The aim of the present study was the assessment of the periodontal therapy in IL-18 level in periodontal disease and health.
\end{abstract}

Materials and methods: Based on clinical attachment loss $(C A L)$, probing pocket depth (PPD), gingival index $(\mathrm{GI})$, and plaque index (PI) patients were divided into three groups: Group I with healthy patients, group II with chronic periodontitis, and group III with posttreatment patients having periodontitis.

Results: Mean PI, PPD, CAL, and gingival crevicular fluid (GCF) volume were significantly higher in groups II and III compared with group I. However, there were no significant differences between GI in groups I, II, and III. The total amount of IL-18 in

\footnotetext{
${ }^{1}$ Department of Periodontics, Dr. Hedgewar Smruti Rugna Seva Mandal Dental College \& Hospital, Hingoli, Maharashtra, India

${ }^{2}$ Department of Dentistry, Government Medical College \& Hospital, Akola Maharashtra, India

${ }^{3}$ Department of Oral Medicine and Radiology, VYWS, Amravati's Dental College \& Hospital, Amravati Maharashtra, India

${ }^{4}$ Department of Conservative and Endodontics, Dr. Hedgewar Smruti Rugna Seva Mandal Dental College \& Hospital, Hingoli Maharashtra, India

${ }^{5}$ Department of Oral Medicine and Radiology, Dr. Hedgewar Smruti Rugna Seva Mandal Dental College \& Hospital, Hingoli Maharashtra, India

${ }^{6}$ Department of Orthodontics, Dr. Rajesh Ramdasji Kambe Dental College \& Hospital, Akola, Maharashtra, India

Corresponding Author: Pawankumar D Tekale, Department of Orthodontics, Dr. Rajesh Ramdasji Kambe Dental College \& Hospital, Akola, Maharashtra, India, Phone: +919970879100 e-mail: pawan0804@gmail.com
}

GCF was significantly higher in group II when compared with groups I and III $(p<0.05)$.

Conclusion: The present study confirmed that the IL-18 level in GCF was lower in healthy patients, higher in periodontally involved patients, and reduced at baseline, 3 and 6 weeks after nonsurgical periodontal therapy.

Clinical significance: The IL-18 might be hypothetically beneficial in distinguishing health from disease and monitoring periodontal disease activity.

Keywords: Interleukin-18, Maharashtra population, Periodontal therapy, Periodontitis.

How to cite this article: Mahajani MJ, Jadhao VA, Wankhade PS, Samson E, Acharya VD, Tekale PD. Effect of Periodontal Therapy on Crevicular Fluid Interleukin-18 Level in Periodontal Health and Disease in Central Maharashtra (India) Population. J Contemp Dent Pract 2017;18(11):1085-1089.

Source of support: Nil

Conflict of interest: None

\section{INTRODUCTION}

Periodontitis is a provocative disease that distracts the connective tissue supporting bone and attachment around the teeth. It results from interactions between periodontal microflora and the multifaceted response of the host. ${ }^{1}$ Initiation and progression of periodontitis are dependent on the presence of virulent microorganisms capable of causing disease. ${ }^{2}$ The incidence and advancement level of periodontal disease rely on the complex interaction between periodontopathic bacteria and cells of host immune system. ${ }^{2}$ These interfaces are facilitated by chemokines and cytokines, which are formed by both resident and emigrant cells at the site of inflammation. Cells that produce cytokines include macrophages/ monocytes, neutrophils, endothelial cells, and fibroblast. ${ }^{3}$ Cytokines lie central to the pathogenesis of ever 
advancing number of disease, including periodontal disease. Researchers have assumed that formation of inappropriate cytokines results in protective immunity, whereas inappropriate cytokines result in tissue destruction and disease progression. ${ }^{1,3-5}$ Interleukin-18 is a proinflammatory cytokine derived from $\mathrm{T}$ cells and produced mainly by cells of Th1/Th0 phenotype but not cells of the Th2 phenotype. ${ }^{4}$

In periodontal patients, IL-7, IL-8, IL12, IL-17, and IL-19 have been testified in both GCF and periodontal tissues. Previous studies have stated the connotation between IL-18 and the pathogenesis of periodontal disease. ${ }^{6,7}$ Further, they stated that IL-18 concentration was higher in periodontal sites where the probing depth was $>6 \mathrm{~mm}$ when compared with healthy sites.

Interleukin- 18 is primarily formed by oral epithelial cells, osteoblasts, adrenal cortex cells, and antigen-presenting cells. ${ }^{7,8}$ Interleukin- 18 is found to be upregulated in various chronic inflammatory diseases, including periodontal disease $^{9,10}$ and has a significant role in advancement of periodontal disease because of its chemotactic, proinflammatory action. This cytokine also surges the rates of neutrophil stimulation. ${ }^{10}$

To the best of our knowledge, none of the studies evaluated the IL-18 level at baseline, after 3 weeks, and after 6 weeks' time in healthy patients, patients with chronic periodontitis, and chronic periodontitis treated with nonsurgical periodontal procedure. The present study is aimed at influence of periodontal therapy on the crevicular fluid IL-18 level in periodontal health and disease in Central Maharashtra population.

\section{MATERIALS AND METHODS}

This present study was conducted in collaboration of the Department of Periodontics, Dr. Hedgewar Smruti Rugna Seva Dental College \& Hospital, Hingoli, and Department of Dentistry, Government Medical College Akola, India. The present study included a total of 90 subjects, between the age group of 25 and 45 years, who reported as outpatients in respective departments mentioned earlier. The patients were given information about study and explained about the procedure. Informed and written consent was obtained from each patient preceding registration in this study. The approval of complete study was obtained from the ethics committee with approval letter no 278/01/2017.

\section{Inclusion Criteria}

Patients aged between 25 and 35 years for both males and females, more than 16 remaining teeth, good general health, mild-to-moderate periodontal disease as evinced by several sites with a probing depth of $5 \mathrm{~mm}$ or more, bleeding on tender probing, and bone loss in radiograph were included in the study.

\section{Exclusion Criteria}

A history of chewing tobacco, betel nuts, smoking; patients having systemic disease like diabetes mellitus, rheumatoid arthritis, etc., were excluded, and patients having bacterial, viral, fungal infections, aggressive periodontitis; pregnant or lactating mothers; and patients on concomitant medical therapy were excluded. The patients who underwent periodontal therapy in past 1 year were also excluded.

A total of 120 patients were checked for full-mouth periodontal probing and loss of attachment of gingiva, and periapical radiographs were done. Out of 120 screened patients, 90 patients were selected according to the inclusion and exclusion criteria. Based on CAL to the close millimeter with a William's probe, PPD, GI, and PI, according to Loe, patients were divided into three groups.

\section{Group I (Healthy)}

Thirty patients with clinically healthy periodontium with no CAL and pocket depth $<3 \mathrm{~mm}$ were selected.

\section{Group II (Chronic Periodontitis)}

Thirty patients with a sign of clinical inflammation with GI more than 1, CAL more than $3 \mathrm{~mm}$ with radiographic evidence of bone loss, and pocket probing depth more than $4 \mathrm{~mm}$ were selected.

\section{Group III (Posttreatment Group)}

Thirty patients with chronic periodontitis treated with scaling and root planing (nonsurgical approach) were selected.

\section{Gingival Crevicular Fluid Collection}

Clinical, radiographic examination and GCF sample collection were done by a single examiner. The patients were seated in dental chair in an upright position, and the location of GCH collection was nominated in all three groups based on CAL to the nearest millimeter with a William's probe, PPD, GI, and PI. The site was air-dried, and cotton roll isolation was done. Further, supragingival plaque was detached without disturbing the marginal gingiva, and a single sterile microcapillary pipette (SigmaAldrich Chemical Company, USA) was used for each selected site and was interleaved into the gingival crevice, till slight resistance was stroked and was kept there for 40 seconds. The quantity of GCF collected was quantitated using Periotron which had been standardized with 1:5 diluted serum. The GCF sample was collected from the 
Effect of Periodontal Therapy on Crevicular Fluid IL-18 Level

selected sites in groups I, II, and III patients at baseline. Further, GCF was collected at interval of 3 and 6 weeks from groups I and II without any periodontal procedure and from group III following periodontal therapy.

The GCF was collected using micropipettes for the accurate level of detectable cytokines. Micropipette has disadvantage of possibility of damage to the marginal gingiva, so utmost care was taken.

\section{IL-18 Estimation}

The samples were analyzed for IL-18 using Quantikine ${ }^{\circledR}$ Human IL-18 Immunoassay kit obtained from R\&D systems, Abingdon, UK (Catalog No. D1700). The samples were analyzed using enzyme-linked immunosorbent assay (ELISA) method. The minimum measurable level of IL-18 (sensitivity of ELISA) was typically $<0.70 \mathrm{pg} /$ $\mathrm{mL}$, while the minimum measurable level of IL-18 was $<10 \mathrm{pg} / \mathrm{mL}$.

The human IL-18 ELISA kit measured human IL-18 by sandwich ELISA. This assay used two monoclonal antibodies against two different epitopes of human IL-18. Samples to be measured or standards were incubated in the microwell coated with antihuman IL-18 monoclonal antibody. After washing, the peroxidase-conjugated antihuman IL-18 monoclonal antibody was added to the microwells and incubated.

\section{Statistical Analysis}

Data obtained from all groups were subjected to statistical analysis. Data analysis was performed using the statistical package Statistical Package for the Social Sciences version 11.5 (SPSS Inc., Chicago Illusion, USA). For all time intervals, the mean cytokine and clinical values from the three groups were used for the purpose of analysis. Differences in cytokine levels between the groups were evaluated by the Mann-Whitney U-test. In each case, the level of significance was set at $p<0.05$. Student's t-test was used to find a significant difference between the two means. Assessment of the clinical measurements before and following therapy was performed by Wilcoxon's signed-rank test. The same test was applied to examine the differences in GCF volume and in GCF IL-18 levels at baseline as well as 3 and 6 weeks without periodontal therapy in groups I and II, following periodontal therapy in group III.

\section{RESULTS}

In the present study, the descriptive data for the population showing standard deviation (SD), mean, GI, PI, periodontal probing depth, and clinical loss of attachment in groups I, II, and III are shown in Table 1. The pairwise comparison stated that there was a statistically
Table 1: Descriptive data for the study participants

\begin{tabular}{llll}
\hline Parameters & $\begin{array}{l}\text { Group I } \\
\text { (mean } \pm S D)\end{array}$ & $\begin{array}{l}\text { Group II } \\
\text { (mean } \pm S D)\end{array}$ & $\begin{array}{l}\text { Group III } \\
\text { (mean } \pm \text { SD) }\end{array}$ \\
\hline $\mathrm{GI}$ & $0.02 \pm 0.04^{*}$ & $3.10 \pm 0.23$ & $2.34 \pm 0.23$ \\
$\mathrm{PI}$ & $0.028 \pm 0.015^{*}$ & $3.43 \pm 0.15$ & $3.03 \pm 0.65$ \\
$\mathrm{PPD}$ & $3.01 \pm 0.55$ & $5.25 \pm 0.083^{*}$ & $4.54 \pm 0.79$ \\
Clinical loss of & 0 & $1.66 \pm 0.032^{*}$ & $1.45 \pm 0.66$ \\
attachment & & & \\
\hline
\end{tabular}

*Statistically significant

significant difference between groups I and II, groups I and III, and groups II and III. The GI and PI scores are significantly lower in group I, higher in group II, and reduced to some extent in group III. The PPD and clinical loss of attachment scores are significantly higher in group II and reduced to some extent in group III.

The GCF volume in each group is shown in Table 2. The concentration (IL-18) in GCF is expressed in $\mathrm{pg} / \mu \mathrm{L}$ as presented in Table 3. Mean IL-18 concentration values were significantly lower in healthy patients compared with chronic periodontitis and following periodontal treatment in chronic periodontitis in group III (at baseline $p<0.01$ and at 6 weeks $p<0.05)$. Mean IL-8 concentration was significantly higher in patients with chronic periodontitis (group II) compared with healthy group (group I; $\mathrm{p}<0.01$ at baseline, 3 and 6 weeks).

Mean PI, PPD, CAL, and GCF volume were significantly higher in groups II and III compared with group I.

Table 2: Gingival crevicular fluid volume $(\mu \mathrm{L})$ of groups I, II, and III patients

\begin{tabular}{llll}
\hline Groups & $\begin{array}{l}\text { Baseline } \\
\text { (mean } \pm S D)\end{array}$ & $\begin{array}{l}3 \text { weeks } \\
\text { (mean } \pm S D)\end{array}$ & $\begin{array}{l}6 \text { weeks } \\
\text { (mean } \pm S D)\end{array}$ \\
\hline I & $0.021 \pm 0.011$ & $0.014 \pm 0.005$ & $0.012 \pm 0.006^{*}$ \\
II & $0.156 \pm 0.031^{* *}$ & $0.05 \pm 0.014^{*}$ & $0.022 \pm 0.015$ \\
III & $0.156 \pm 0.017^{* *}$ & $0.05 \pm 0.013^{*}$ & $0.022 \pm 0.011$ \\
\hline
\end{tabular}

At baseline $p<0.01$, at 6 weeks $p<0.05$; ${ }^{*} p<0.05$ between groups I, II, and III; ${ }^{* *} p<0.01$ between groups I, II and III

Table 3: Concentration of IL-18 in GCF as well as PPD, CAL, $\mathrm{PI}$, and $\mathrm{GI}$ in groups I, II, and III

\begin{tabular}{|c|c|c|c|c|}
\hline \multirow[b]{2}{*}{ Groups } & \multirow[b]{2}{*}{$\begin{array}{l}\text { Clinical } \\
\text { parameter }\end{array}$} & \multicolumn{3}{|c|}{$I L(p g / \mu L)$} \\
\hline & & $\begin{array}{l}\text { Baseline } \\
(\text { mean } \pm S D)\end{array}$ & $\begin{array}{l}3 \text { weeks } \\
(\text { mean } \pm S D)\end{array}$ & $\begin{array}{l}6 \text { weeks } \\
(\text { mean } \pm S D)\end{array}$ \\
\hline \multirow[t]{4}{*}{1} & $\mathrm{GI}$ & $2.02 \pm 0.00$ & $0.19 \pm 0.28$ & $0.01 \pm 0.00^{*}$ \\
\hline & $\mathrm{PI}$ & $2.22 \pm 0.41$ & $0.66 \pm 0.18^{*}$ & $0.07 \pm 0.35$ \\
\hline & PPD & $3.56 \pm 0.65$ & $3.27 \pm 0.34^{*}$ & $2.45 \pm 0.56$ \\
\hline & CAL & $3.11 \pm 1.68$ & $2.82 \pm 1.34^{*}$ & $2.15 \pm 1.01$ \\
\hline \multirow[t]{4}{*}{ II } & $\mathrm{Gl}$ & $3.04 \pm 0.58$ & $2.47 \pm 0.86$ & $1.21 \pm 0.42^{*}$ \\
\hline & $\mathrm{PI}$ & $3.06 \pm 0.41$ & $2.41 \pm 0.26$ & $1.36 \pm 0.54^{*}$ \\
\hline & PPD & $5.30 \pm 0.57$ & $3.98 \pm 1.231^{*}$ & $3.12 \pm 0.66$ \\
\hline & CAL & $5.35 \pm 1.68$ & $4.93 \pm 1.52$ & $4.57 \pm 1.33^{*}$ \\
\hline \multirow[t]{4}{*}{ III } & GI & $3.23 \pm 0.23$ & $2.47 \pm 0.48$ & $1.41 \pm 0.42^{*}$ \\
\hline & $\mathrm{Pl}$ & $3.07 \pm 0.41$ & $2.34 \pm 0.66^{*}$ & $1.33 \pm 0.67$ \\
\hline & PPD & $5.33 \pm 0.66$ & $4.01 \pm 1.665^{*}$ & $2.44 \pm 0.23^{*}$ \\
\hline & $\mathrm{CAL}$ & $6.44 \pm 1.33$ & $4.54 \pm 0.32$ & $3.02 \pm 1.01^{*}$ \\
\hline
\end{tabular}

${ }^{*} p<0.05$ between groups I and II, groups II and III, and groups I and III 
However, there were no significant differences between GI in groups I, II, and III. The total amount of IL-18 in GCF was significantly higher in group II when compared with groups I and III.

\section{DISCUSSION}

Periodontitis is provocative and distracts the connective tissue attachment and supporting bone present surrounding the teeth. It usually results from interactions between periodontal microflora and the complex response of the host. ${ }^{1,3}$ The ILs are a group of cytokines that have complex immunological roles including proliferation, migration, growth, and differentiation of cells. ${ }^{4,6}$ Interleukin- 18 is a proinflammatory cytokine and associate of the IL-1 family that has the ability to encourage either Th1 or Th2 cells in reaction to Gram-negative infections. ${ }^{8}$ It has only been scrutinized in a small number of studies to date, looking at different loci. The advancement of gingivitis to periodontitis has been a topic of strong search for several eras. An exploration for conceivable key cytokines tangled in this process might elucidate the mechanisms intricate in the start of the collagen breakdown and, consequently, the loss of attachment.

Interleukin-18 is recognized as a cytokine that rouses both Th1 and Th2 response reliant on the presence or absence of IL-12. In the presence of IL-12, IL-18 mainly persuades the manufacture of interferon-gamma-producing Th1 cells, and in absenteeism of IL-12, it shifts the response to IL-4 manufacturing Th2 cells. ${ }^{8-10}$ Hence, IL-18 appears to be a latent factor that can play a key role in amendable the immune responses intricate in the initiation and advancement of periodontal disease.

In a study conducted by Figueredo et al., it has been evidenced that IL-1b might play a role as a factor between gingivitis in periodontitis patients and gingivitis in otherwise healthy patients. ${ }^{8}$ Formerly, Johnson and Serio $^{6}$ revealed the connotation between IL-18 and the pathogenesis of periodontal disease. They confirmed that IL-18 concentration was higher in gingival biopsies adjacent to sites where the probing depth was $>6 \mathrm{~mm}$ when compared with healthy sites.

Pradeep et $\mathrm{al}^{4}$ carried out a research with the exploration of the role of the Th1 cytokines with concomitant surge in IL-17 and IL-18 in periodontitis as compared with the healthy individuals. Figueredo et $\mathrm{al}^{9}$ stated that there is elevated concentration of IL-18 in GCF of periodontitis patients. Ozçaka et $\mathrm{al}^{10}$ found IL-18 to be increased in shallow inflamed sites in periodontitis patients when compared with gingivitis sites in control patients.

The present study publicized significant differences in IL-18 concentrations in healthy patients, patients with periodontitis, and patients with periodontitis treated with nonsurgical periodontal therapy $(\mathrm{p}<0.05)$. Patients with chronic periodontitis presented a significant decrease in IL-18 level after treatment. The result advocated that IL-18 levels augmented in GCF from a healthy state to periodontitis as the severity of the disease increased. The pairwise comparison showed that these differences were statistically significant between groups I and II, groups I and III, and groups II and III ( $p<0.05$; Table 3$)$. The levels in GCF were positively interrelated with PPD and CAL in groups II and III.

The research conducted by Udagawa et $\mathrm{al}^{11}$ and Horwood et $\mathrm{al}^{12}$ demonstrated that IL-18 seems to have a pleiotropic activity, wherein IL-18 acts as an inhibitor of osteoclast manufacture through indirect effects enabled by T-cell production of granulocyte macrophage colonystimulating factor. de Campos et $\mathrm{al}^{13}$ evaluated the IL-18 level in GCF following nonsurgical periodontal therapy. The study found that the IL-18 level is higher in periodontitis and decreases with concomitant nonsurgical periodontal approach. Nair et $\mathrm{al}^{14}$ concluded that, as the inflammation increased, there was a rise in the level of IL-18 and level of IL-18 decreases following periodontal therapy. This may clarify the abridged levels of IL-18 in gingival tissues from periodontitis patients in group III after periodontal therapy as perceived in the present study. Our results are in accordance with the results of these previous studies. ${ }^{11-14}$ The present study confirmed that the IL-18 level in GCF was lower in group I, higher in periodontally involved patients in group II, and proportionally reduced after the nonsurgical periodontal therapy in group III at baseline, 3 and 6 weeks.

A limitation of our study is that the levels of IL-18 in patients with severe attachment loss were not evaluated. Further studies need to be done at a time interval of more than 6 weeks to appraise the level of IL-18 in GCF after nonsurgical and surgical periodontal therapy. The studies need to be done correlating these cytokine levels with different degrees of chronic periodontitis severity and aggressive periodontitis.

\section{CONCLUSION}

The activity of cytokines reliant on enlistment, interaction, and stimulation of immune-competent cells can elucidate the site-specific nature of cytokine manifestation. The verdicts of raised IL-18 levels in chronic periodontitis patients compared with healthy patients suggest a close connotation between salivary IL-18 and periodontal status further proportionally abridged after the nonsurgical periodontal therapy over time period at baseline, 3 and 6 weeks. Thus, IL-18 might be potentially useful in distinctive health from disease and observing periodontal disease activity. 


\section{REFERENCES}

1. Newman, MG.; Takei, H.; Klokkevold, PR.; Carranza, FA. Carranza's clinical periodontology. 10th ed. St. Louis (MO): Saunders; 2012. p. 349-350.

2. Kinane DF, Lappin DF. Clinical, pathological and immunological aspects of periodontal disease. Acta Odontol Scand 2001 Jul;59(3):154-160.

3. Honda T, Domon H, Okui T, Kajita K, Amanuma R, Yamazaki K. Balance of inflammatory response in stable gingivitis and progressive periodontitis lesions. Clin Exp Immunol 2006 Apr;144(1):35-40.

4. Pradeep AR, Hadge P, Chowdhry S, Patel S, Happy D. Exploring the role of Th1 cytokines: Interleukin-17 and interleukin-18 in periodontal health and disease. J Oral Sci 2009 Jun;51(2):261-266.

5. Chaudhari AU, Byakod GN, Waghmare PF, Karhadkar VM. Correlation of levels of interleukin- $1 \beta$ in gingival crevicular fluid to the clinical parameters of chronic periodontitis. J Contemp Dent Pract 2011 Jan;12(1):52-59.

6. Johnson RB, Serio FG. Interleukin-18 concentrations and the pathogenesis of periodontal disease. J Periodontol 2005 May;76(5):785-790.

7. Biet F, Locht C, Kremer L. Immunoregulatory functions of interleukin 18 and its role in defense against bacterial pathogens. J Mol Med (Berl) 2002 Mar;80(3):147-162.
8. Nakanishi K, Yoshimoto T, Tsutsui H, Okamura H. Interleukin-18 regulates both Th1 and Th2 responses. Annu Rev Immunol 2001 Apr;19:423-474.

9. Figueredo CM, Rescala B, Teles RP, Teles FP, Fischer RG, Haffajee AD, Socransky SS, Gustafsson A. Increased interleukin-18 in gingival crevicular fluid from periodontitis patients. Oral Microbiol Immunol 2008 Apr;23(2):173-176.

10. Ozçaka O, Nalbantsoy A, Buduneli N. Interleukin-17 and interleukin-18 levels in saliva and plasma of patients with chronic periodontitis. J Periodontal Res 2011 Oct;46(5):592-598.

11. Udagawa N, Horwood NJ, Elliott J, Mackay A, Owens J, Okamura H, Kurimoto M, Chambers TJ, Martin TJ, Gillespie MT. Interleukin-18 (interferon-gamma-inducing factor) is produced by osteoblasts and acts via granulocyte/macrophage colonystimulating factor and not via interferon-gamma to inhibit osteoclast formation. J Exp Med 1997 Mar;185(6):1005-1012.

12. Horwood NJ, Elliott J, Martin TJ, Gillespie MT. IL-12 alone and in synergy with IL-18 inhibits osteoclast formation in vitro. J Immunol 2001 Apr;166(8):4915-4921.

13. de Campos BO, Fischer RG, Gustafsson A, Figueredo CM. Effectiveness of non-surgical treatment to reduce il-18 levels in the gingival crevicular fluid of patients with periodontal disease. Braz Dent J 2012;23(4):428-432.

14. Nair V, Bandyopadhyay P, Kundu D, Das S. Estimation of interleukin-18 in the gingival crevicular fluid and serum of Bengali population with periodontal health and disease. J Indian Soc Periodontol 2016 May-Jun;20(3):260-264. 